\title{
Automatic Position Information of Web-Openings of Building Using Minimized Strain Energy Topology Optimization
}

\author{
Dongkyu Lee ${ }^{1}$ and Soomi Shin ${ }^{2}$ \\ ${ }^{1}$ Department of Architectural Engineering, Sejong University, 98 Gunja-dong, Gwangjin-gu, Seoul 143-747, Republic of Korea \\ ${ }^{2}$ Research Institute of Industrial Technology, Pusan National University, Jangjeon-dong, Geumjeong-gu, \\ Busan 609-735, Republic of Korea \\ Correspondence should be addressed to Soomi Shin; shinsumi82@pusan.ac.kr
}

Received 7 January 2015; Accepted 19 March 2015

Academic Editor: Antônio G. B. de Lima

Copyright (C) 2015 D. Lee and S. Shin. This is an open access article distributed under the Creative Commons Attribution License, which permits unrestricted use, distribution, and reproduction in any medium, provided the original work is properly cited.

\begin{abstract}
This study presents a new engineering practice and idea that material topology optimization results may be utilized to optimally decide the positions of web-openings of structural members in a building structure. Material topology optimization utilizes element densities as design parameters, that is, nominal constructional material, and then optimal material distributions of densities between voids (0) and solids (1) in a given design domain represent the determination of topology and shape. That means that regions with element density values become occupied by solids in a design domain, while there are only void phases in regions where no density values exist. Therefore, the void regions of topology optimization results may provide design information that decides appropriate depositions of web-opening in structure. Numerical examples demonstrate the efficiency of the present methodological design information using optimization techniques to automatically resolve the building design of proper deposition of web-openings.
\end{abstract}

\section{Introduction}

Currently, a web-opening system which is used in modern architectural buildings and civil structures has been developed in order to obtain functional aspects of structural design such as planned layouts and special efficiency of deposition of facilities. This system can reduce buried spaces which result from sparing expenses of construction per floor in facilities, especially high-rise buildings, by cutting down the amount of material. The structural system of webopenings was fundamentally introduced by Bower [1] in 1968 who investigated ultimate strength of beam structures. Since then, Ward [2] has introduced structural behavioral comparisons between composite and noncomposite beams with web-openings. Improvement problems of bending and shear stiffness of composite beams with web-openings have been treated by Redwood and Demirdjian [3]. In Korea, the determination of proper depositions and numbers and shapes of web-openings were investigated, and immediately bending and shear response analyses were carried out. Then their experiments have been carried out in steel and concrete structures by Eon et al. [4] in 1985, Koo [5] in 1998, and Lee et al. [6] in 2003.

According to abovementioned researches, it was verified that web-openings in structures can become substantially problematic in structural safety such as a decline of member stiffness. Since the openings are mainly located in web parts, the decline of shear stiffness especially becomes more obvious than that of bending stiffness. For example, a Vierendeel effect is that an occurrence of a bending moment around webopenings results in a reduction of shear resistance of crosssections; furthermore, a local torsion buckling may occur in web parts of members due to neighboring web-openings.

In general, when web-openings with varied shapes and sizes are placed in members of a given structure, structural stability of the members can be investigated through strain energy, that is, stiffness of structure. Since the web-openings which have an influence on stiffness of structure have varied shapes, numbers, sizes, and so on, optimization techniques that yield maximal stiffness of structure under defined design conditions can be employed for appropriate web-opening's deposition in structure. Although shapes, numbers, and sizes 
of web-openings have to be also considered in the structural design, optimal deposition of web-openings into members is a main interest in this study because shapes, numbers, and sizes must be treated secondly after the determination of depositions of web-openings.

In this study, a topology optimization technique introduced by Bendsøe and Kikuchi [7] in 1988 is utilized in order to decide optimal depositions of web-openings. Topology optimization of structures yields optimal topology as well as optimal shape for global structural systems. In discretization of continuous design domain, a density is defined as a material property of each element, that is, an optimization design parameter. Therefore optimal shape and topology are represented by optimal density distribution contours which have maximal stiffness of structure.

Until now, there have been no determinant and official criteria for structural design with web-openings domestically, and the deposition of web-openings has been designed according to engineers' experiences and usual practices. Thus the objective of the present work is to verify whether applications of the topology optimization approach provide a new structural design method for proper web-opening's depositions. In this method, minimal strain energy or maximal stiffness is defined as objective function, which is satisfied with volume or mass constraints. Under the optimization conditions, an appropriate case with the greatest stiffness of feasible cases of deposition of web-openings may be designed according to optimal results. In advance, feasible parts of web-opening's depositions into void phases have to be sought through results of optimal density distributions of structure without web-openings.

In this study, proper web-opening's depositions of linear elastostatic structures are investigated using density distribution method or Solid Isotropic Microstructure with Penalization for Intermediate Density, that is, SIMP [8-16] of topology optimization methods, and efficiency of the proposed method is demonstrated.

\section{Strain Energy Minimization Based Topology Optimization Problem}

2.1. Optimization Problem. In design domain $\Omega_{x} \subseteq \mathfrak{R}^{n}(n=$ 2) which dominates linear elastostatic structures, topology optimization problems are defined as follows:

$$
\begin{array}{ll}
\text { Minimize: } & f=\left[-\frac{1}{2} \int_{\Omega_{x}} \boldsymbol{\varepsilon}^{T}(\mathbf{u}) \mathbf{C}(E) \boldsymbol{\varepsilon}(\mathbf{u}) d \Omega_{x}\right] \\
\text { Subject to: } & \int_{\Omega_{x}} \boldsymbol{\varepsilon}^{T}(\mathbf{u}) \mathbf{C}(E) \boldsymbol{\varepsilon}(\delta \mathbf{u}) d \Omega_{x} \\
& =\int_{\Omega_{x}} \mathbf{b}^{T} \delta \mathbf{u} d \Omega_{x}+\int_{\Gamma_{t}} \mathbf{t}^{T} \delta \mathbf{u} d \Gamma_{t} \\
& \int_{\Omega_{x}} d \Omega \leq V_{0},
\end{array}
$$

where (1) denotes an objective function $f$, that is, minimal strain energy or maximal stiffness. $\boldsymbol{\varepsilon}, \mathbf{C}$, and $\mathbf{u}$ are, respectively, strains, material tensors, and displacements. Equations
(2) and (3) are optimization constraints. Equation (2) is equilibrium. $\delta \mathbf{u}, \mathbf{b}$, and $\mathbf{t}$ are virtual displacements, body forces, and traction forces, respectively. Equation (3) is a volume constraint, and $V_{0}$ is the limit of feasible volumes in the design domain.

2.2. Density Distribution Method. In topology optimization, material characteristics of each element which are employed through discretization of continuous design domain are defined as element densities. The densities are utilized as design parameters of topology optimization. It is represented as a simple penalty form related to Young's modulus. This is regarded as a density distribution method or SIMP using design domain concepts. Since optimal solutions of SIMP obtain superiority in terms of engineering's aspect and manufacture's ability, it has been practically used for topological optimal design.

The penalty relation between Young's modulus and density is written as

$$
\mathbf{E}_{i}=E_{0}\left(\frac{\Phi_{i}}{\Phi_{0}}\right)^{k}, \quad k \geq 1,0 \leq \Phi_{i}, \quad \Phi_{0} \leq 1,
$$

where $\mathbf{E}_{i}$ and $\boldsymbol{\Phi}_{i}$ denote Young's modulus and density of element $i$, respectively. The penalty parameter $k$ is used for SIMP. $E_{0}$ and $\Phi_{0}$ are, respectively, nominal values of Young's modulus and density.

Suppose that the defined structural system follows plane stress state with isotropic materials; material tensor $\mathbf{C}_{i}$ of element $i$ can be written including (4) as

$$
\mathbf{C}_{i}=\frac{E_{i}\left(\boldsymbol{\Phi}_{i}\right)}{\left(1-v^{2}\right)}\left\{\begin{array}{ccc}
1 & \nu_{0} & 0 \\
\nu_{0} & 1 & 0 \\
0 & 0 & \frac{1-v_{0}}{2}
\end{array}\right\},
$$

where $v_{0}$ is a nominal Poisson's ratio.

According to topology optimization problems defined as (1) and (2), optimal solutions are material density distribution contours with maximal stiffness. The material density values consist of void phases ( 0 , white), solid phases (1, black), and intermediate phases $(0<$ value $<1$, gray) in domain $\Omega$ as shown in Figure 1.

2.3. Sensitivity Analysis. Since displacement fields depend on optimization design parameter $\mathbf{s}$, a total sensitivity of objective function fin terms of $\mathbf{s}$ is written as a partial derivative introduced by Haug et al. [17] in 1986 as follows:

$$
\nabla_{s} \mathbf{f}=\nabla_{s}^{\mathrm{ex}} \mathbf{f}+\bar{\nabla}_{u} \mathbf{f}^{T} \nabla_{s} \mathbf{u}
$$

where $\nabla_{s}^{\text {ex }} \mathbf{f}$ and $\bar{\nabla}_{u} \mathbf{f}^{T} \nabla_{s} \mathbf{u}$ denote an explicit and implicit partial derivative terms, respectively.

Suppose that, in discrete processes, body forces $\mathbf{b}$, traction forces $\mathbf{t}$, differential tensor $\mathbf{L}$, and Jacobi matrix are independent of design parameter s, and finally the total sensitivity formulation of objective function $\mathbf{f}$ is simply rewritten as follows:

$$
\nabla_{s} \mathbf{f}=-\frac{1}{2} \mathbf{u}_{i} \int_{\Omega_{i}} \mathbf{B}_{i}^{T} \nabla_{s} \mathbf{C}_{i}(\boldsymbol{\Phi}) \mathbf{B}_{i} d \Omega_{i} \mathbf{u}_{i}
$$




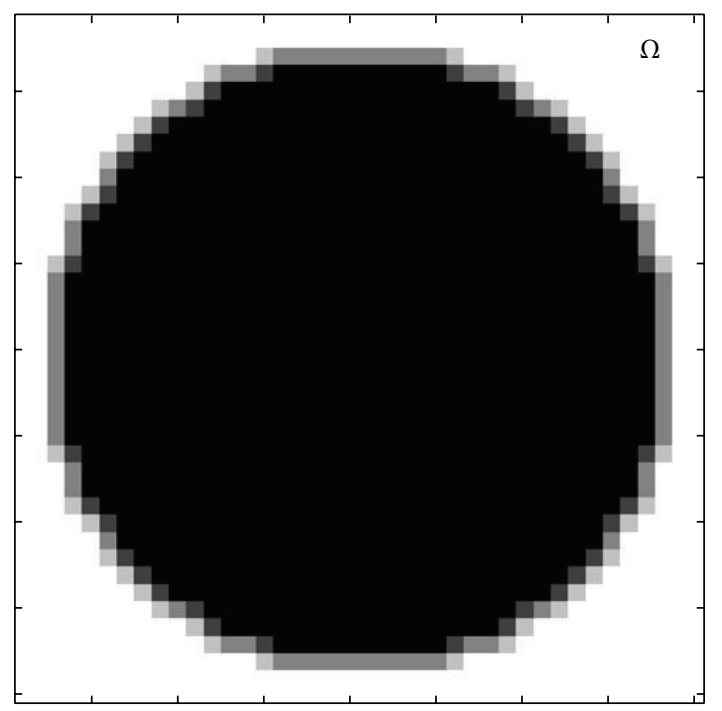

Solid $=1$

$0<$ intermediate state $<1$

$\square$ Void $=0$

FIGURE 1: Boundary representations as material density distributions in topology optimization.

where $\mathbf{u}_{i}, \mathbf{B}_{i}$, and $\mathbf{C}_{i}$ are nodal displacement vector, operator matrix, and material tensor of element $i$.

\section{Numerical Algorithm for Determination of Optimal Depositions of Web-Openings}

The numerical algorithm for optimal depositions of webopenings using topology optimization results is shown in Figure 2, which is extended in [18] and the procedures of deposition design of web-openings are as follows:

(1) It is assumed that web-opening's shapes, numbers, and sizes are not considered as variables of structural design. They might be treated in future works. Here, one square of $8 \times 8$ finite elements is only fixed as webopening's geometry and number.

At first, topology optimization of nominal structure without web-openings is carried out. Through yielded material density distributions, void phases are searched and web-opening's deposition models are decided into the parts.

(2) Topology optimization is executed according to each model of web-opening's depositions which is decided in (1).

(3) Seek a web-opening's model with the smallest strain energy of all optimal solutions obtained in (2). It means that the structure with this model includes maximal stiffness and gets the greatest structural safety.

(4) The optimal deposition result of web-openings is used as profitable information for web-opening's design.

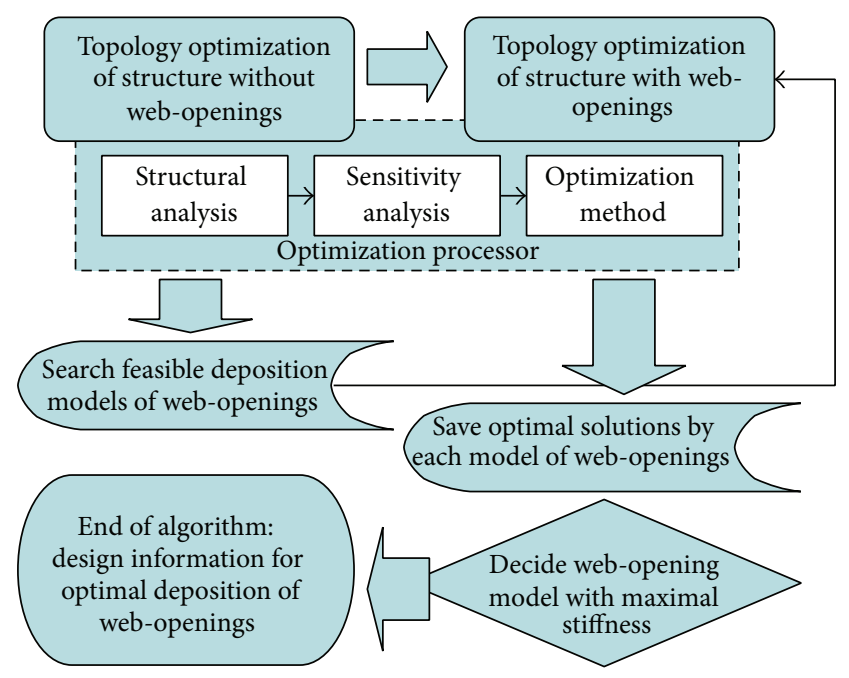

FIGURE 2: Algorithm for optimal deposition of web-openings.

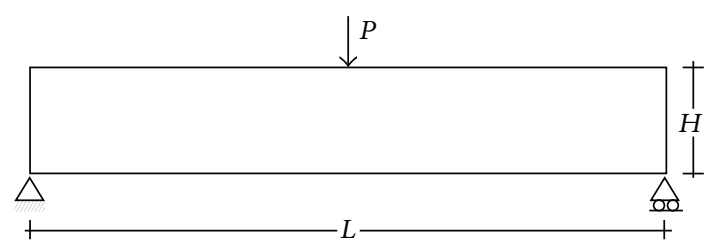

Figure 3: Analytical model: a MBB-beam.

\section{Numerical Applications and Discussion}

\subsection{Determination of Optimal Depositions of Web-Openings in MBB-Beam}

4.1.1. Stage 1: Initialization of Design Conditions and Topology Optimization Problems. As a 2-dimensional linear elastostatic problem, topology optimization of MBB(Messerschmitt-Bölkow-Blohm-) beam [19] is carried out. In MBB-beam, the size ratio of $L$ (length) : $H$ (height) is $6: 1$ and a concentrated load is applied at the center side of the upper part. MBB-beam is simply supported by a roller and hinge at left and right sides, respectively. It is shown in Figure 3.

In continuous design domain $(120 \mathrm{~cm} \times 20 \mathrm{~cm})$, square finite elements of $120 \times 20$ are discretized. As topology optimization problems, an objective function is minimal strain energy $(\mathrm{N} \cdot \mathrm{m})$ and a volume constraint is restricted by $30 \%$ of total volumes. Nominal values of Young's modulus of steel, Poisson's ratio of steel, and an external force are $E_{0}=$ $2.1 \times 10^{6} \mathrm{~kg} / \mathrm{cm}^{2}, \nu_{0}=0.3$, and $P_{0}=360 \mathrm{~N}$, respectively. The penalty parameter [20] for SIMP is $k=5.0$. In MBBbeam, one square of $8 \mathrm{~cm} \times 8 \mathrm{~cm}$ (finite elements of $8 \times 8$ ) is considered as conditions of web-opening.

4.1.2. Stage 2: Execution of Topology Optimization of $M B B$ Beam without Web-Openings and Selection of Feasible Models of Web-Opening's Depositions. Topology optimization results of MBB-beam without web-openings are represented by material density distribution contours and shown in Figure 4. 


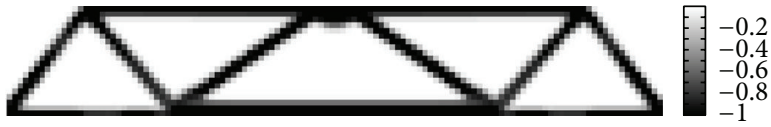

(a) Optimal material density distribution contours

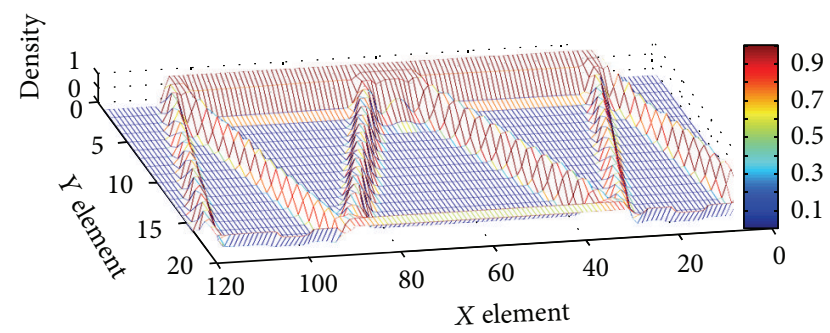

(b) 3D optimal density function

FIGURE 4: Optimal solutions of SIMP of MBB-beam without web-openings.

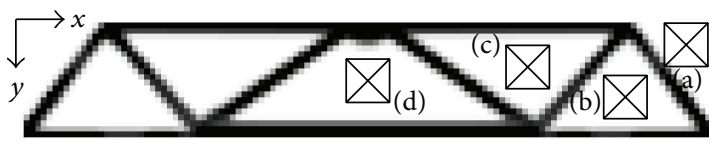

FIGURE 5: Models (types) of a d of depositions of web-opening.

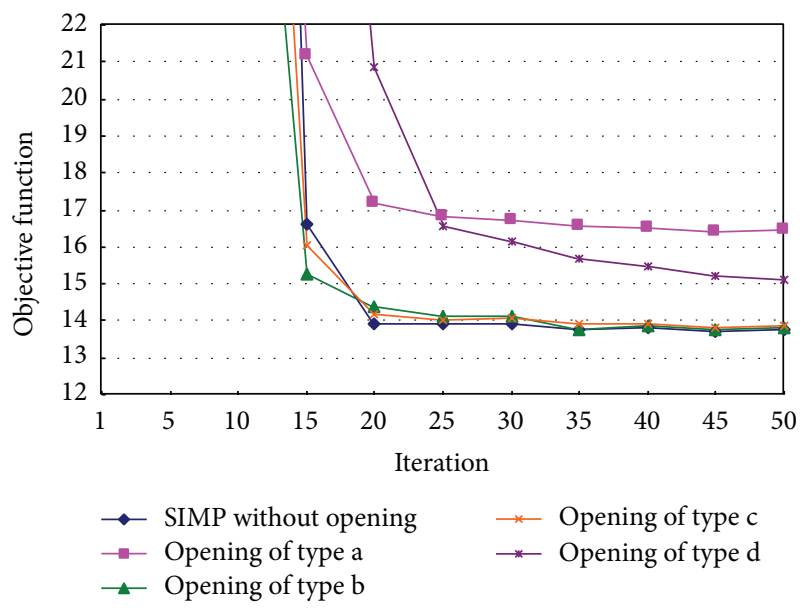

Figure 6: Convergence histories of objective function in case of models a d of web-opening.

TABLE 1: Models (types) of depositions of web-opening.

\begin{tabular}{lcc}
\hline Model (type) & el $x$ & el $y$ \\
\hline $\mathrm{a}$ & $113 \sim 120$ & $1 \sim 8$ \\
$\mathrm{~b}$ & $102 \sim 109$ & $10 \sim 17$ \\
$\mathrm{c}$ & $85 \sim 92$ & $5 \sim 12$ \\
$\mathrm{~d}$ & $57 \sim 64$ & $7 \sim 14$ \\
\hline
\end{tabular}

It can be found from Figure 4 that feasible regions of webopenings are presented by models of 4 kinds due to symmetry of MBB-beam. The models of web-openings are illustrated in Figure 5 and Table 1. Here, el $x$ and el $y$ denote $x$ and $y$ coordinates of elements, respectively.

4.1.3. Stage 3: Execution of Topology Optimization of Each Model and Determination of a Web-Opening's Model with Maximal Stiffness. Figure 6 shows convergence histories of objective function of strain energy at 50 iterations in topology optimization of MBB-beam with models of web-opening.

It can be seen from Figure 6 that the convergence history of SIMP without web-opening is similar to that of SIMP with web-openings of models $b$ and $c$. The fact emphasizes the necessity of web-openings in structure with respect to the economical use of materials under structural safety.

Figures 7(a) and 7(b) illustrate strain energy values of structure in an initial stage and a final stage of topology optimization, respectively. Note that results of the initial stage of the optimization, that is, model a: very good, models b and d: not good, and model c: bad, are different from those of the final stage, that is, models b and c: very good, model d: not good, and model a: bad.

The results of the initial stage are not reliable since the optimization cannot be achieved from the beginning and requires proper iterations or times in order to be satisfied with optimization conditions and obtain optimal solutions.

Note that engineers must be concerned with the final results of optimization. Therefore it can be found that model $\mathrm{b}$ or $\mathrm{c}$ is the best choice but model a is the worst one as final measurement of each model.

Figure 8 illustrates continuous intermediate density distributions by models of web-opening's depositions. It can be found that the increase of strain energy at the edges of webopening is different according to each model.

\subsection{Determination of Optimal Depositions of Web-Openings in Beam-to-Column Connection}

\subsubsection{Stage 1: Initialization of Design Conditions and Topology} Optimization Problems. As the second test, a linear elastostatic structure with beam-to-column connection [21] is considered. The geometry, boundary, and loading conditions of the analytical model are shown in Figure 9.

The design domain $(160 \mathrm{~cm} \times 80 \mathrm{~cm})$ of dash lines is discretized as finite elements of $80 \times 40$. As topology optimization problems, an objective function is minimal strain energy $(\mathrm{N} \cdot \mathrm{m})$ and a volume constraint is restricted by $27 \%$ of total volumes. Nominal values of Young's modulus of steel, Poisson's ratio of steel, and an external force are $E_{0}=$ $2.1 \times 10^{6} \mathrm{~kg} / \mathrm{cm}^{2}, v_{0}=0.3$, and $P_{0}=360 \mathrm{~N}$, respectively. The penalty parameter for SIMP is $k=5.0$. 


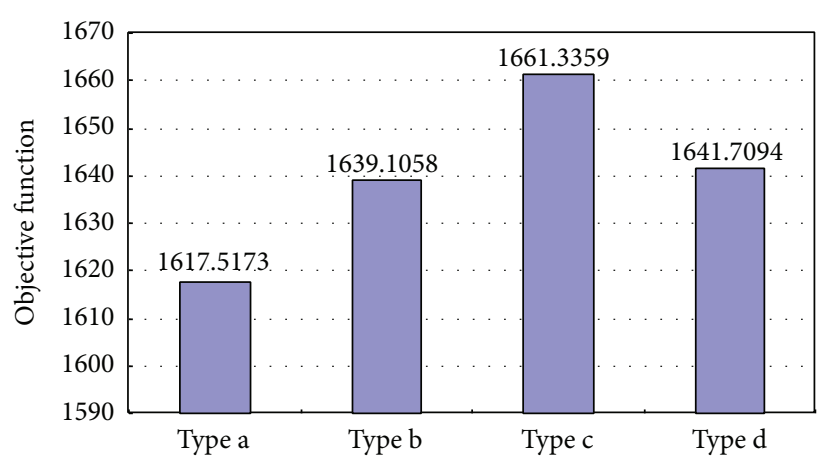

(a) Initial stage

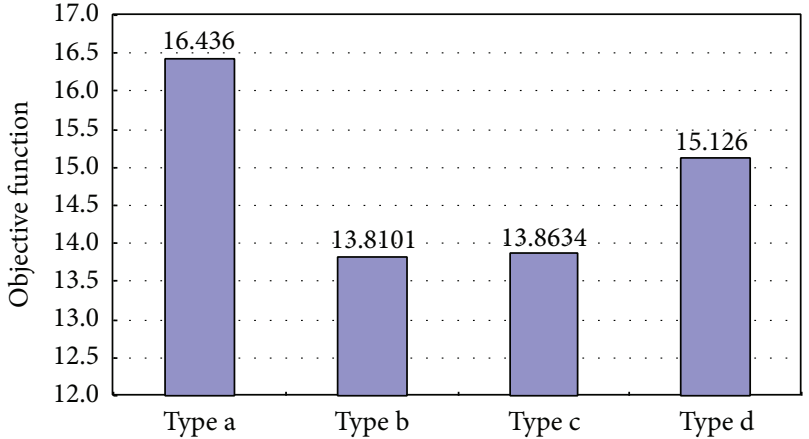

(b) Final result

FIgURE 7: Strain energy values by models of a d of depositions of web-opening.

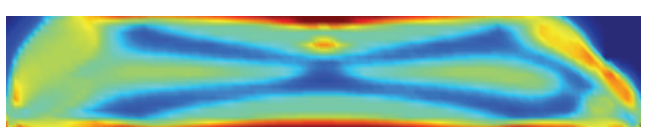

(a) Type a

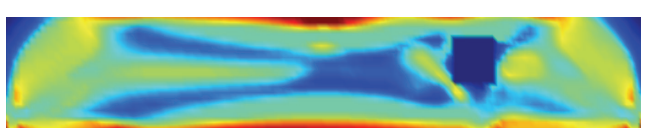

(c) Type c

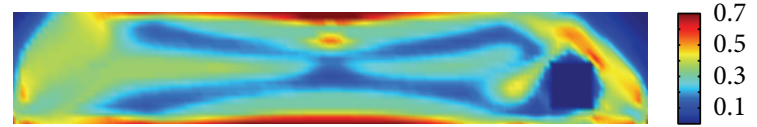

(b) Type b

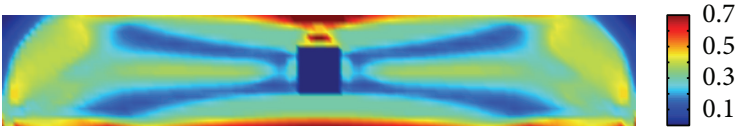

(d) Type d

FIGURE 8: Continuous intermediate density distributions by models a d of web-opening's depositions.

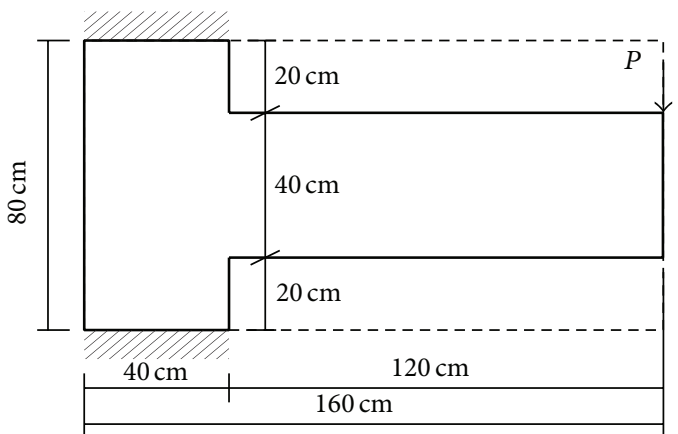

Figure 9: Analytical model: a structure with beam-to-column connection.

In the structure with beam-to-column connection, one square of $16 \mathrm{~cm} \times 16 \mathrm{~cm}$ (finite elements of $8 \times 8$ ) is considered as conditions of web-opening.

4.2.2. Stage 2: Execution of Topology Optimization of Beamto-Column without Web-Openings and Selection of Feasible Models of Web-Opening's Depositions. Figure 10 shows results of topology optimization without considering web-opening such as truss shapes [22]. Feasible models of web-opening's deposition can be investigated and they are models $a, b, c, d$, $\mathrm{e}$, and $\mathrm{g}$ as shown in Figure 11. Model $\mathrm{f}$ is infeasible but here it is considered for comparison with feasible models.
TABLE 2: Models (types) of depositions of web-opening.

\begin{tabular}{lcc}
\hline Model (type) & el $x$ & el $y$ \\
\hline a & $73 \sim 80$ & $22 \sim 29$ \\
$\mathrm{~b}$ & $58 \sim 65$ & $14 \sim 21$ \\
$\mathrm{c}$ & $41 \sim 48$ & $19 \sim 26$ \\
$\mathrm{~d}$ & $20 \sim 27$ & $16 \sim 23$ \\
$\mathrm{e}$ & $6 \sim 13$ & $1 \sim 8$ \\
$\mathrm{f}$ & $6 \sim 13$ & $17 \sim 24$ \\
$\mathrm{~g}$ & $6 \sim 13$ & $33 \sim 40$ \\
\hline
\end{tabular}

Table 2 shows deposition coordinates of models of webopening in design domain. Here, el $x$ and el $y$ denote $x$ and $y$ coordinates of elements.

4.2.3. Stage 3: Execution of Topology Optimization of Each Model and Determination of a Web-Opening's Model with Maximal Stiffness. The convergence histories of objective function in topology optimization of the structure with beam-to-column connection with each model of Figure 11 and Table 2 are shown in Figure 12. Figures 12(a) and 12(b) illustrate global and local convergence histories of objective function, respectively.

Figures 13(a) and 13(b) show histograms of strain energy of an initial stage and a final stage of Figure 12(b), respectively. It is obviously verified from Figure 12(a) that the selection of a model $\mathrm{f}$ is inappropriate for deposition of web-opening 


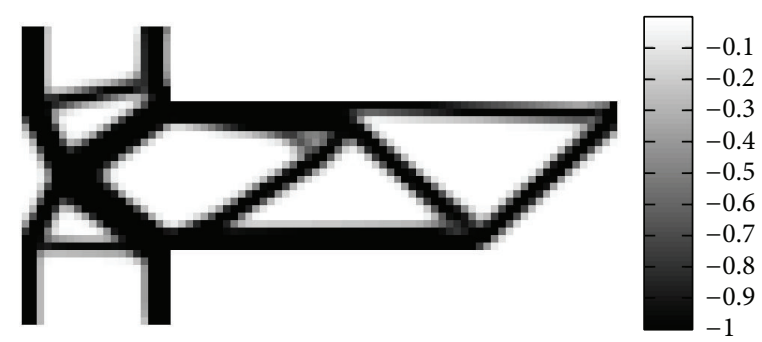

(a) Optimal material density distribution contours

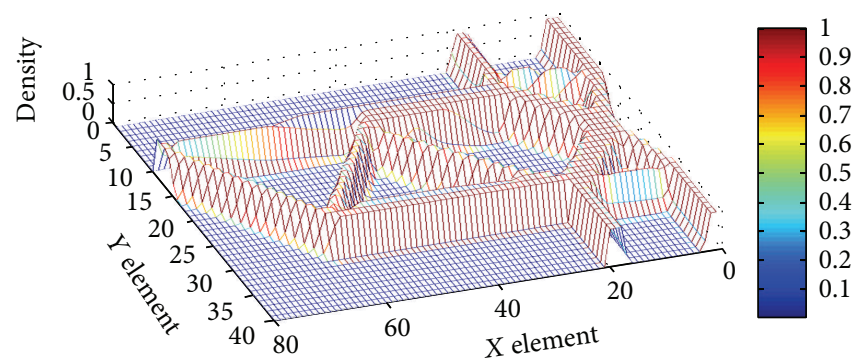

(b) 3D optimal density function

FIGURE 10: Optimal solutions of SIMP of a structure with beam-to-column connection without web-opening.

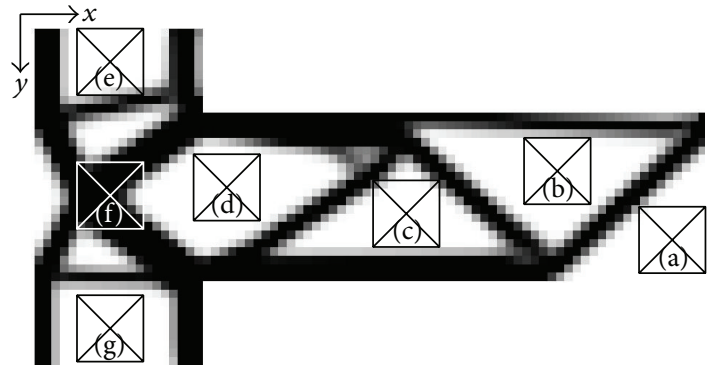

FIGURE 11: Models (types) of a g of depositions of web-opening.

since model f gets the greatest converged strain energy values compared with other models.

From comparisons of minimal strain energy in Figures 12(b) and 13(b), it can be seen that a model e is the best deposition of web-opening but a model $\mathrm{d}$ is the worst one. The order of superior models is $e>g>c>a>b>d>f$.

Figure 14 shows continuous intermediate density distributions by models a e and $\mathrm{g}$. In the structure with beam-tocolumn connection, it can be found that larger strain energy occurs in edges of beam-column connection than in parts of web-opening.

Figure 15 illustrates comparisons of intermediate density distribution between a model $\mathrm{f}$ and a case without webopening. It is seen that the existence of web-opening results in the increase of strain energy and the more material density in that part is required.

\section{Conclusions}

Structural optimization is a sequential and mathematical technique to achieve the maximum or minimum of objective function that is satisfied with defined constraints in structural problems. This method can optimize the design variables such as topologies, shapes, and sizes for optimal solutions. In particular topology optimization method that yields optimal topologies for the solution utilizes design variables of constant densities into finite elements and its solution is represented as optimal distributions of material densities between 0 and 1 . It means that the positions with densities in design domain have to be occupied by materials for structural stiffness and there is no requirement of materials

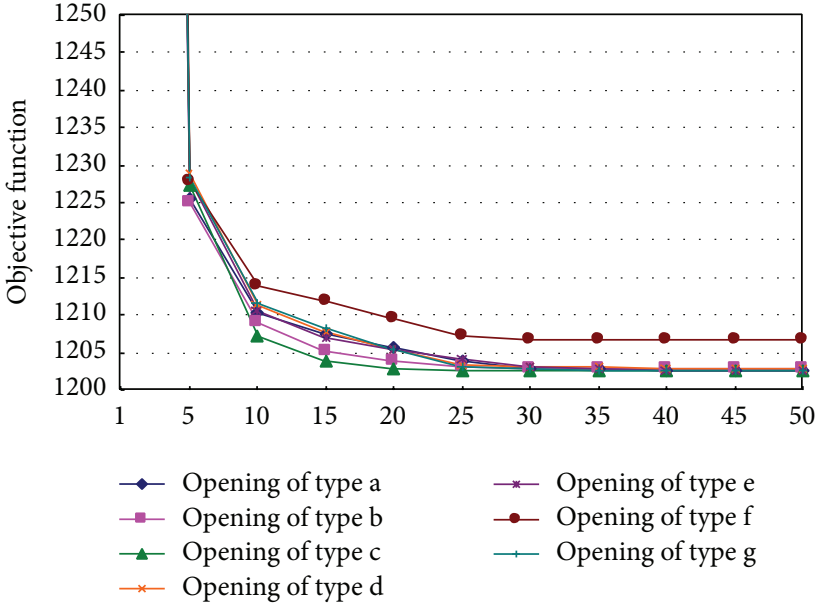

(a) Iteration (global scale)

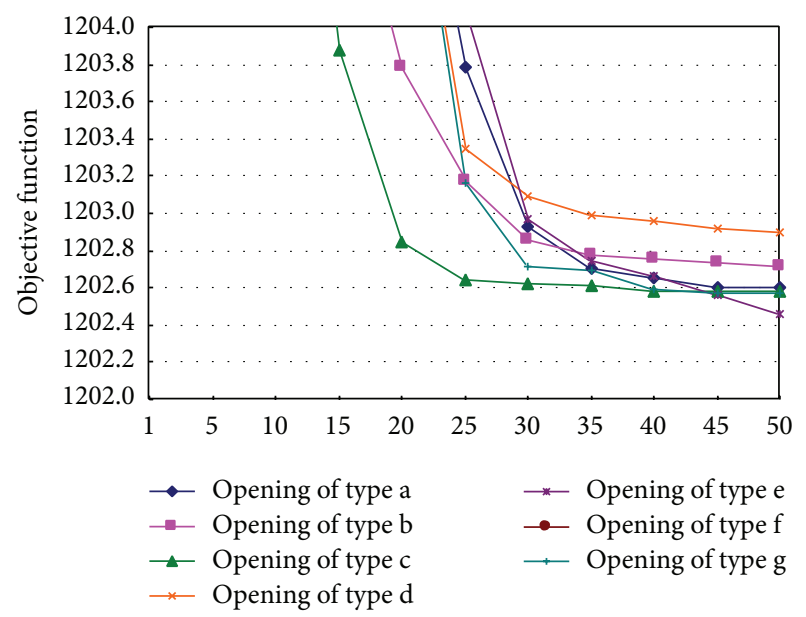

(b) Iteration (local scale)

FIGURE 12: Convergence histories of objective function in case of models a $\sim$ g of web-opening.

in regions where no densities exist. Therefore the void regions of topology optimization results can become design information for appropriate deposition of web-opening into which it has no material.

Until now the topology optimization technique has been used for optimal design of structures; however in this study 


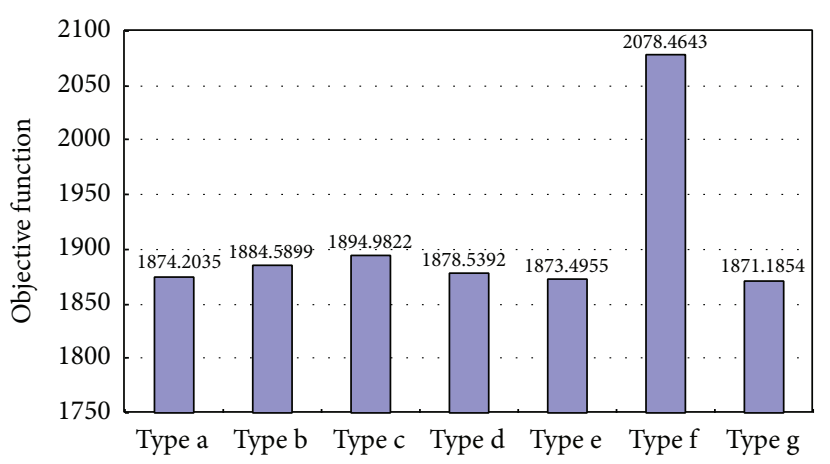

(a) Initial condition

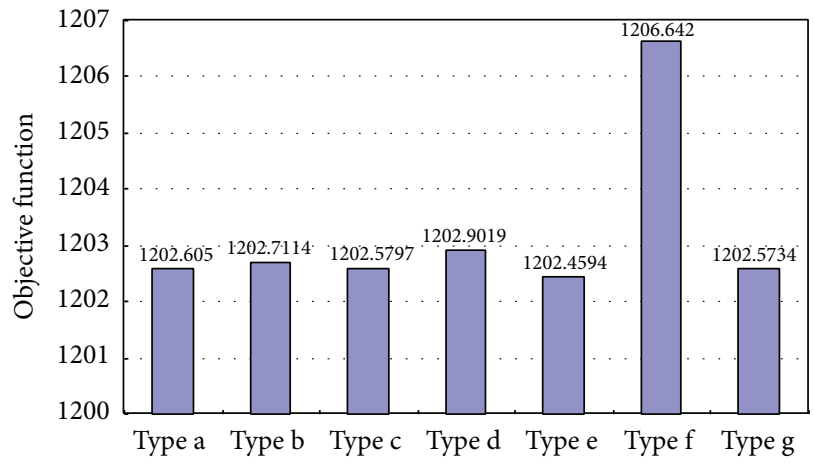

(b) Final result

FIGURE 13: Strain energy values by models of a g of depositions of web-opening.

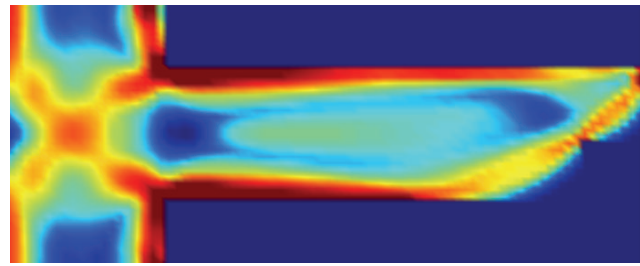

(a) Model a

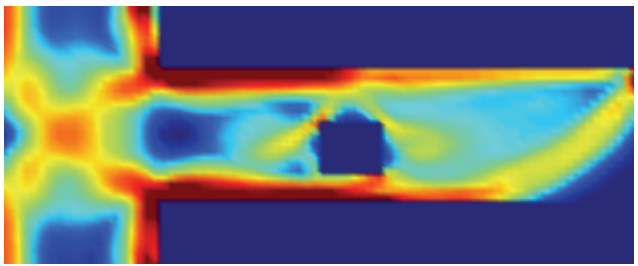

(c) Model c

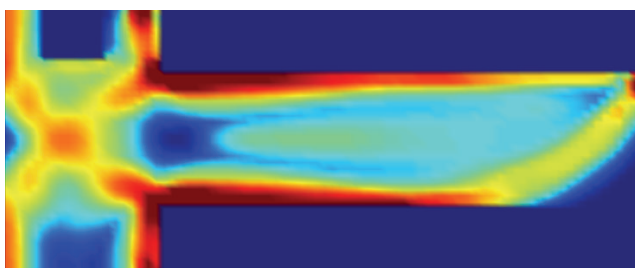

(e) Model e

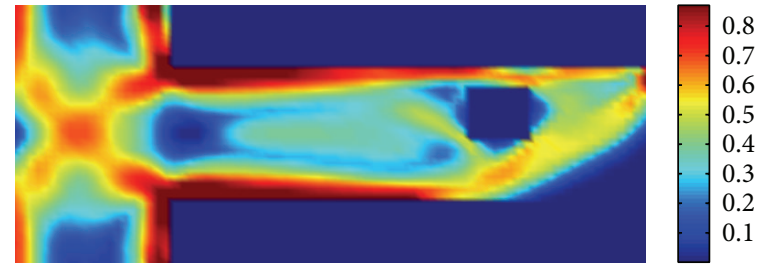

(b) Model b

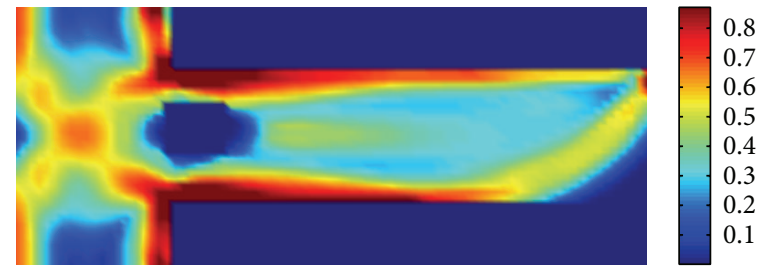

(d) Model d

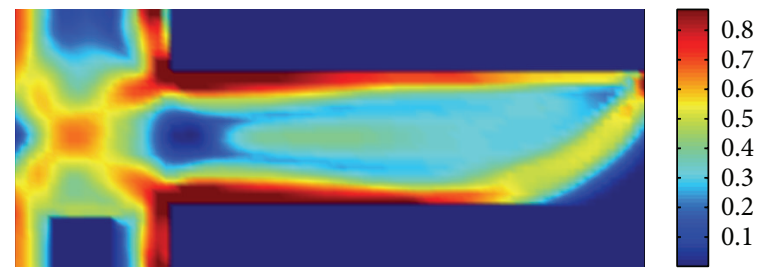

(f) Model g

Figure 14: Continuous intermediate density distributions by models a e and g of web-opening's depositions.

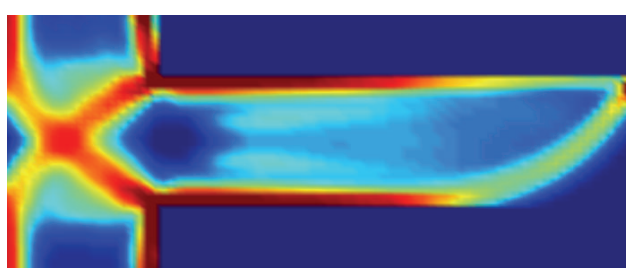

(a) Original SIMP without web-opening
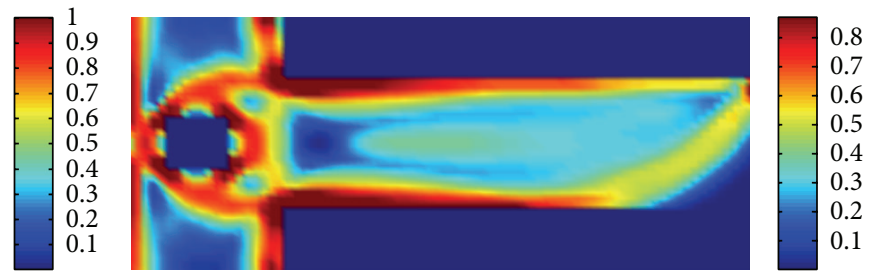

(b) Model $\mathrm{f}$

FIGURE 15: Continuous intermediate density distributions between original SIMP without web-opening and a model $\mathrm{f}$. 
it is proposed that the present method is an engineering practice and idea to be utilized for decision of proper webopening's position. Numerical examples of beam-to-column and simple beam with linear elastostatic problem demonstrate efficiency of the technique for proper web-opening's deposition.

In the web-opening of MBB-beam, the best structure with maximum stiffness is type $b$ according to converged objective function values. In the web-opening of beamto-column connection, the best structure with maximum stiffness is type e according to converged objective function values. As can be seen in the two results, structures with web-openings avoiding regions of many optimal material density distributions have a good performance with respect to structural stiffness.

In the future, the determination of varied variables such as shape, number, and size of web-opening as well as decision of appropriate disposition of web-opening would be also investigated in order to establish official criteria of structural design of web-opening.

\section{Conflict of Interests}

The authors declare that there is no conflict of interests regarding the publication of this paper.

\section{Acknowledgment}

This research was supported by Grants nos. 2013R1A1A2057502 and 2014R1A1A3A04051296 from the National Research Foundation of Korea (NRF) funded by the Korea government.

\section{References}

[1] J. E. Bower, "Ultimate strength of beams with rectangular holes," ASCE Journal of the Structural Division, vol. 94, no. 6, pp. 13151337, 1968.

[2] J. K. Ward, Design of Composite and Non-Composite Cellular Beams, The Steel Construction Institute Publication no. 100, The Steel Construction Institute, 1990.

[3] R. G. Redwood and S. Demirdjian, "Castellated beam web buckling in shear," Journal of Structural Engineering, vol. 124, no. 10, pp. 1202-1207, 1998.

[4] D. S. Eon, H. J. Suh, and Y. B. Kim, "An experimental study on the reinforced concrete beams with web opening," Journal of Architectural Institute of Korea, vol. 5, no. 2, pp. 337-340, 1985.

[5] H. S. Koo, "An experimental study on characteristics of reinforced concrete beams with the rectangular opening," Journal of Architectural Institute of Korea, vol. 14, no. 7, pp. 11-19, 1998.

[6] E. T. Lee, H. J. Shim, and K. H. Chang, "Local buckling and plastic behavior of perforated steel members under cyclic loading," Journal of Architectural Institute of Korea, vol. 19, no. 11, pp. 23-32, 2003.

[7] M. P. Bendsøe and N. Kikuchi, "Generating optimal topologies in optimal design using a homogenization method," Computer Methods in Applied Mechanics and Engineering, vol. 71, no. 1, pp. 197-224, 1988.
[8] M. P. Bendsøe, "Optimal shape design as a material distribution problem," Structural Optimization, vol. 1, no. 4, pp. 193-202, 1989.

[9] H. P. Mlejnek, "Some aspects of the genesis of structures," Structural Optimization, vol. 5, no. 1-2, pp. 64-69, 1992.

[10] R. J. Yang and C. H. Chuang, "Optimal topology design using linear programming," Computers \& Structures, vol. 52, no. 2, pp. 265-275, 1994.

[11] D. K. Lee, J. H. Lee, J. H. Kim, and U. Starossek, "Investigation on material layouts of structural diagrid frames by using topology optimization," KSCE Journal of Civil Engineering, vol. 18, no. 2, pp. 549-557, 2014.

[12] D. K. Lee, J. H. Lee, K. H. Lee, and N. S. Ahn, "Evaluating topological optimized layout of building structures by using nodal material density based bilinear interpolation," Journal of Asian Architecture and Building Engineering, vol. 13, no. 2, pp. 421-428, 2014.

[13] D. K. Lee, J. H. Lee, and N. S. Ahn, "Generation of structural layout in use for ' $0-1$ ' material considering $n$-order eigenfrequency dependence," Materials Research Innovations, vol. 18, supplement 2, pp. S2-833-S2-839, 2014.

[14] D. K. Lee, S. M. Shin, H. J. Park, and S. S. Park, “Topological material distribution evaluation for steel plate reinforcement by using CCARAT optimizer," Structural Engineering and Mechanics, vol. 51, no. 5, pp. 793-808, 2014.

[15] D. K. Lee and S. M. Shin, "Extended-finite element method as analysis model for Gauss point density topology optimization method," Journal of Mechanical Science and Technology, vol. 29, no. 4, pp. 1341-1348, 2015.

[16] D. K. Lee and S. M. Shin, "Optimising node density-based structural material topology using eigenvalue of thin steel and concrete plates," Materials Research Innovations, vol. 19, supplement 5, pp. S5-1241-S5-1245, 2015.

[17] E. J. Haug, K. K. Choi, and V. Komkov, Design Sensitivity Analysis of Structural Systems, Academic Press, Orlando, Fla, USA, 1986.

[18] O. Sigmund, "A 99 line topology optimization code written in Matlab," Structural and Multidisciplinary Optimization, vol. 21, no. 2, pp. 120-127, 2001.

[19] D. Khoza, Topology optimization of plate-like structures [Ph.D. thesis], University of Pretoria, Pretoria, South Africa, 2006.

[20] X.-P. Wang and S.-W. Yao, "Topology optimization with a penalty factor in optimality criteria," Advanced Materials Research, vol. 317-319, pp. 2466-2472, 2011.

[21] D. K. Lee and S. M. Shin, "Advanced high strength steel tube diagrid using TRIZ and nonlinear pushover analysis," Journal of Constructional Steel Research, vol. 96, pp. 151-158, 2014.

[22] D. K. Lee and S. M. Shin, "High tensile UL700 frame module with adjustable control of length and angle," Journal of Constructional Steel Research, vol. 106, pp. 246-257, 2015. 

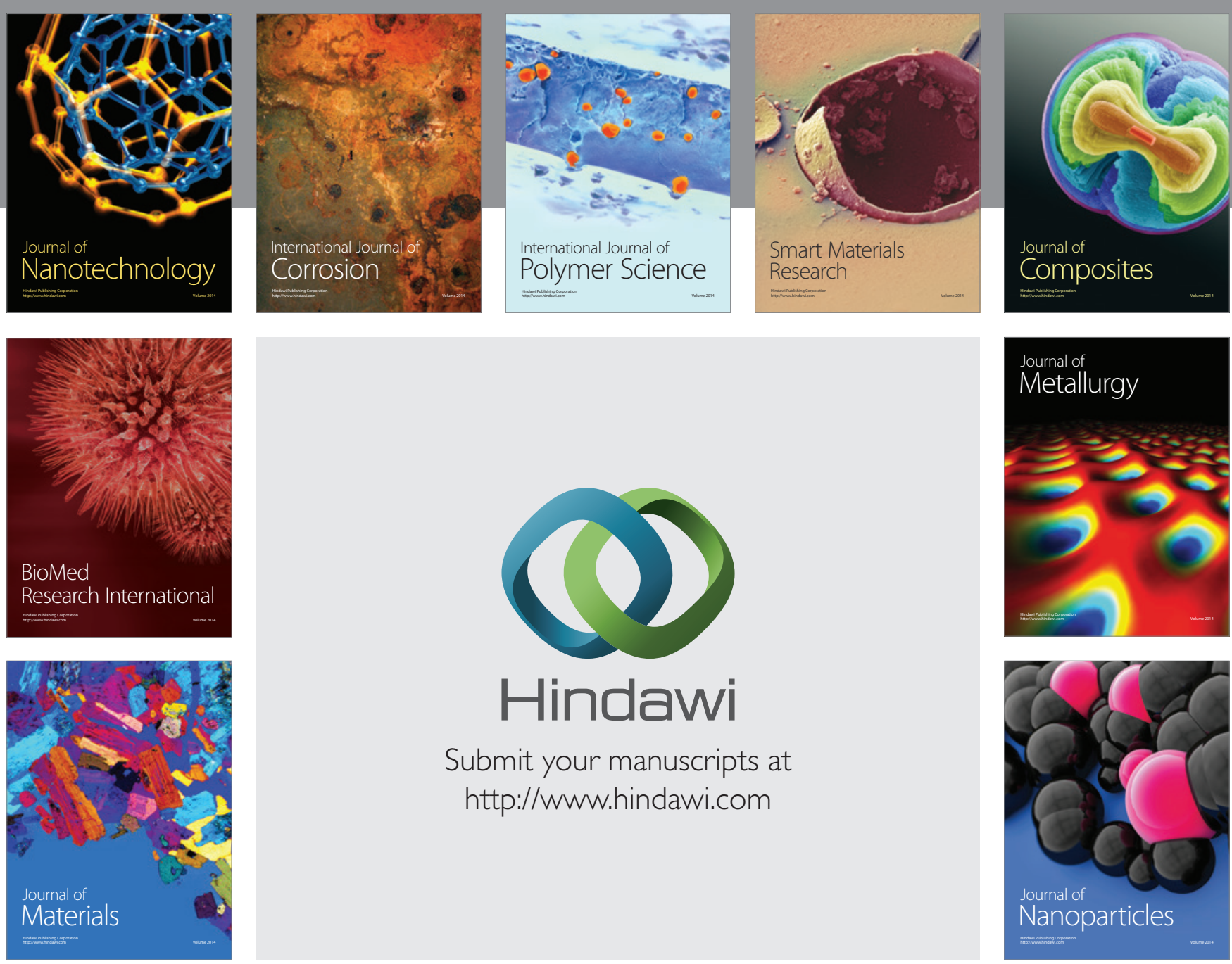

Submit your manuscripts at http://www.hindawi.com
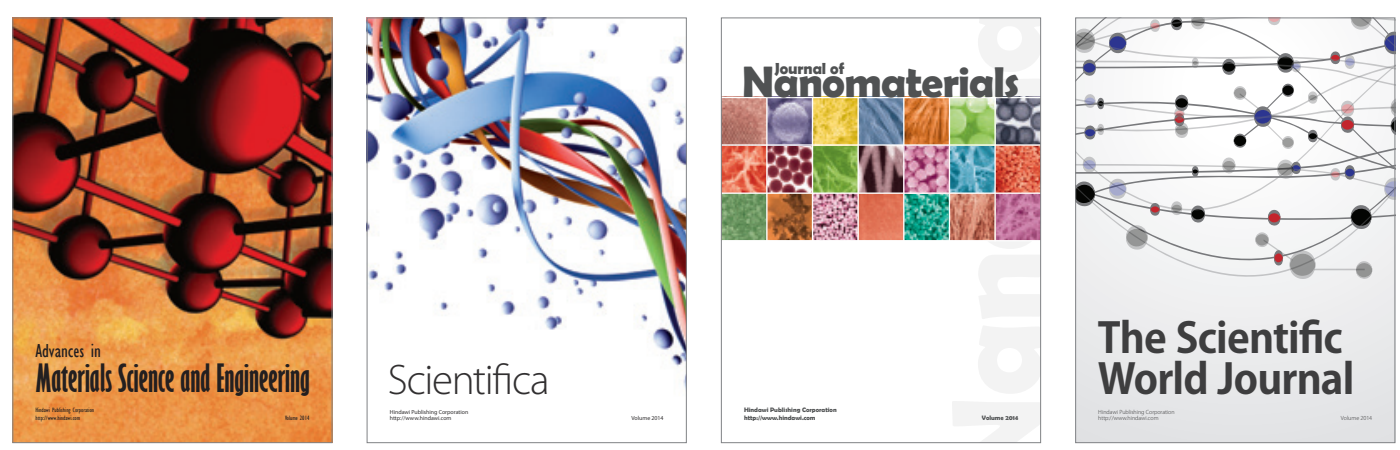

\section{The Scientific World Journal}
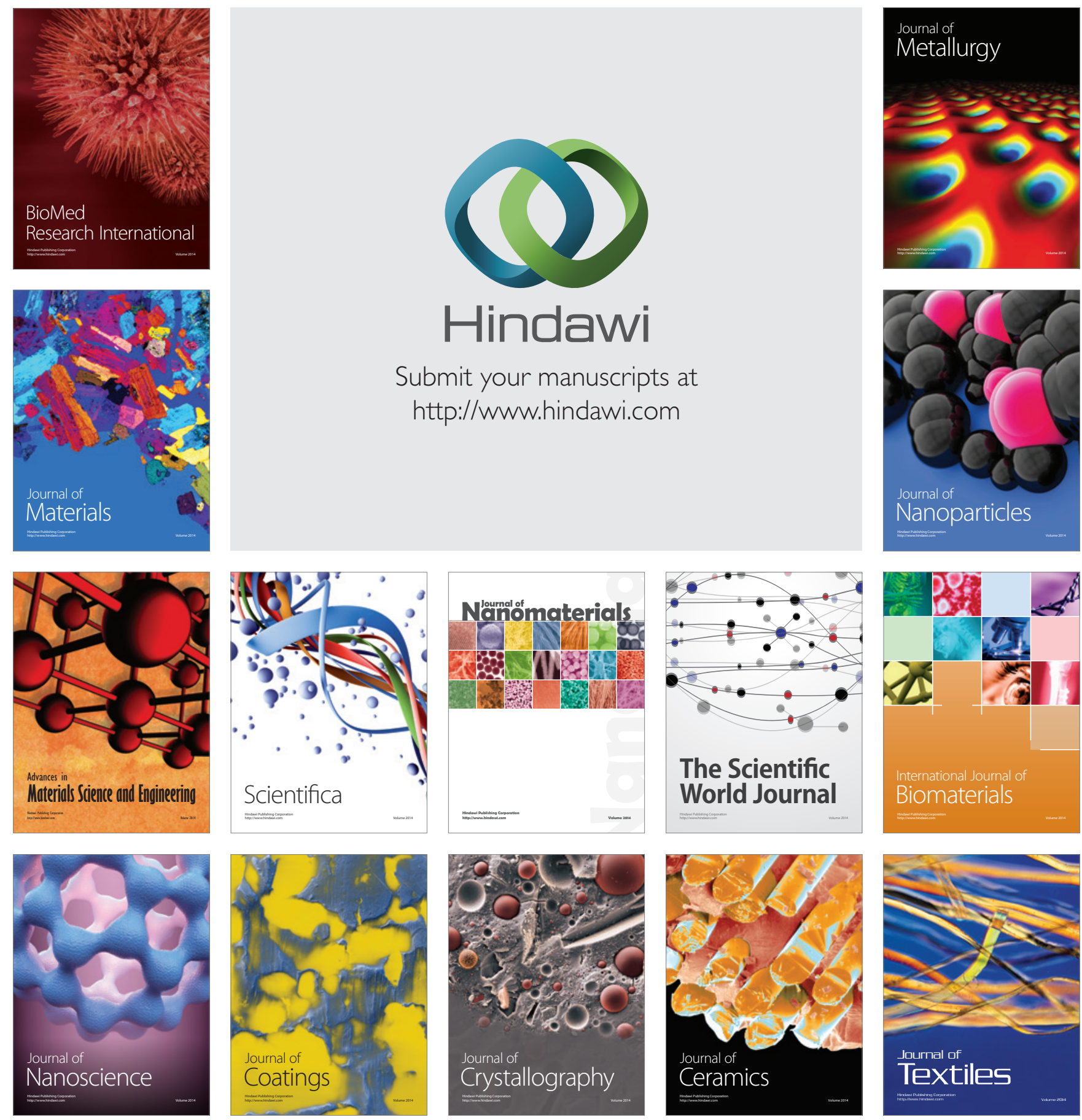